\title{
Crystallographic, DFT and docking (Cathepsin B) studies on an organotellurium(IV) compound
}

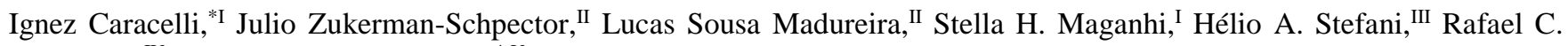 \\ Guadagnin $^{\text {IV }}$ and Edward R. T. Tiekink ${ }^{*}$ V \\ ${ }^{\text {I } U n i v e r s i d a d e ~ F e d e r a l ~ d e ~ S a ̃ o ~ C a r l o s, ~ B i o M a t, ~ D e p a r t a m e n t o ~ d e ~ F i ́ s i c a, ~ C . P . ~ 676, ~ S a ̃ o ~ C a r l o s, ~ S P, ~ 13565-905, ~ B r a z i l ~}$ \\ II Universidade Federal de São Carlos, Laboratório de Cristalografia, Estereodinâmica e Modelagem Molecular, Departamento de Química, \\ C.P. 676, São Carlos, SP, 13565-905, Brazil \\ III Universidade de São Paulo, Departamento de Farmácia, Faculdade de Ciências Farmacêuticas, São Paulo, SP, Brazil \\ IV Universidade Federal de São Paulo, Instituto e Ciências Ambientais, Químicas e Farmacêuticas, UNIFESP, Diadema, SP, Brazil \\ ${ }^{v}$ Sunway University, Centre for Crystalline Materials, Faculty of Science and Technology, 47500 Bandar Sunway, Selangor Darul Ehsan, \\ Malaysia
}

Received; accepted

Keywords: Organotellurium / DFT / docking / crystal structure analysis / X-ray diffraction

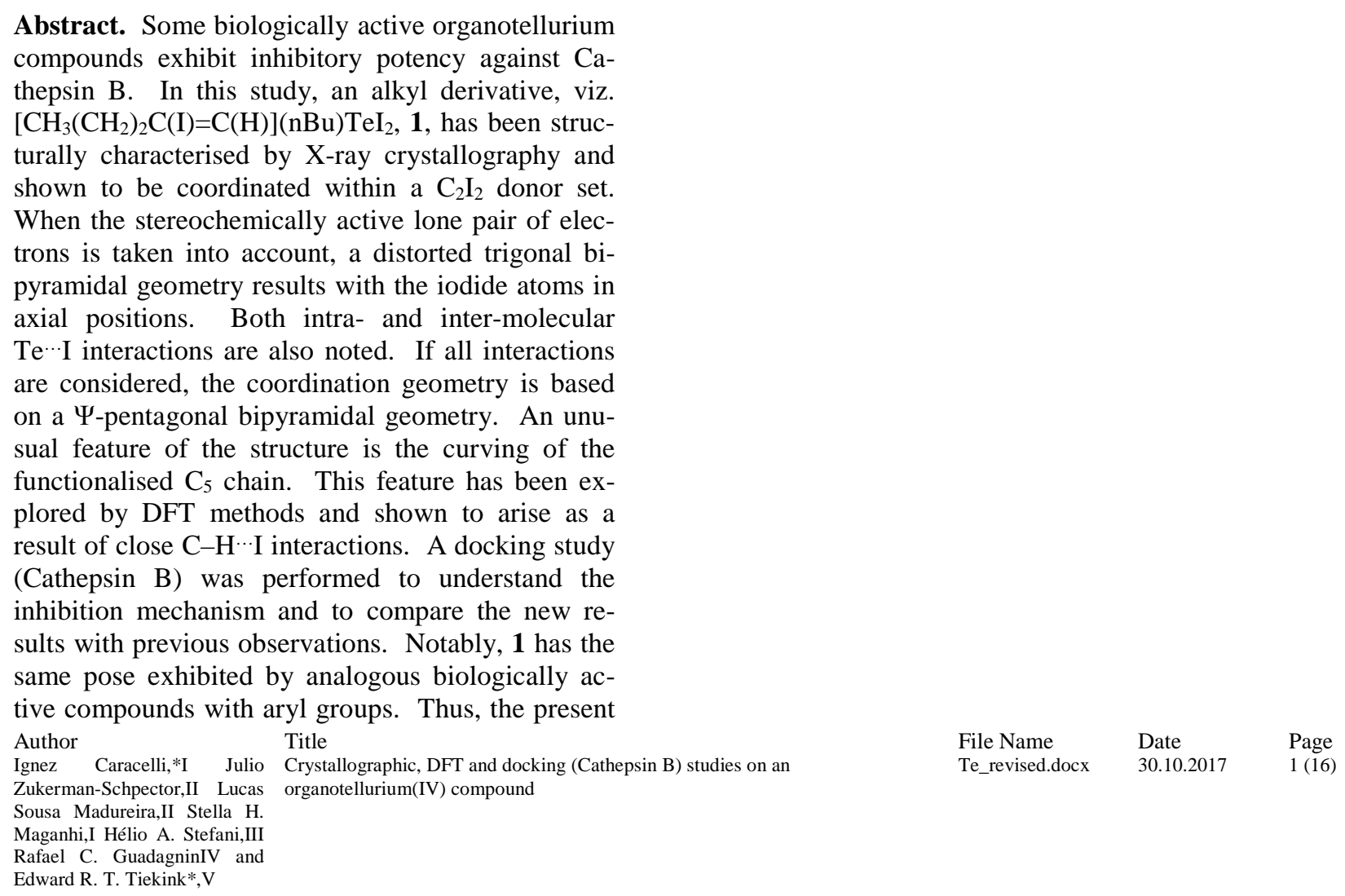


study suggests that (alkyl) ${ }_{2} \mathrm{TeX}_{2}$ compounds should also be evaluated for biological activity.

* Correspondence authors: ignez@df.ufscar.br (I.C.); edwardt@sunway.edu.my (E.R.T.T.)

\section{Introduction}

The lysosomal cysteine protease, Cathepsin B, hereafter $\mathrm{Cat} \mathrm{B}$, is responsible for the degradation and processing of proteins in living organisms $[1,2]$. The structure is characterised by a thiol in the cysteine residue, Cys29, and a histidine, His 199, in the catalytic site [3, 4], and therefore, in the context of metal-based drugs, offers the opportunity for coordination to metal centres. Herein, the interaction of an organotellurium(IV) compound, diiodo(2-iodopent1-en-1-yl)butyl- $\lambda^{4}$-tellane (1), Fig. 1 , with Cat B is investigated employing docking studies.

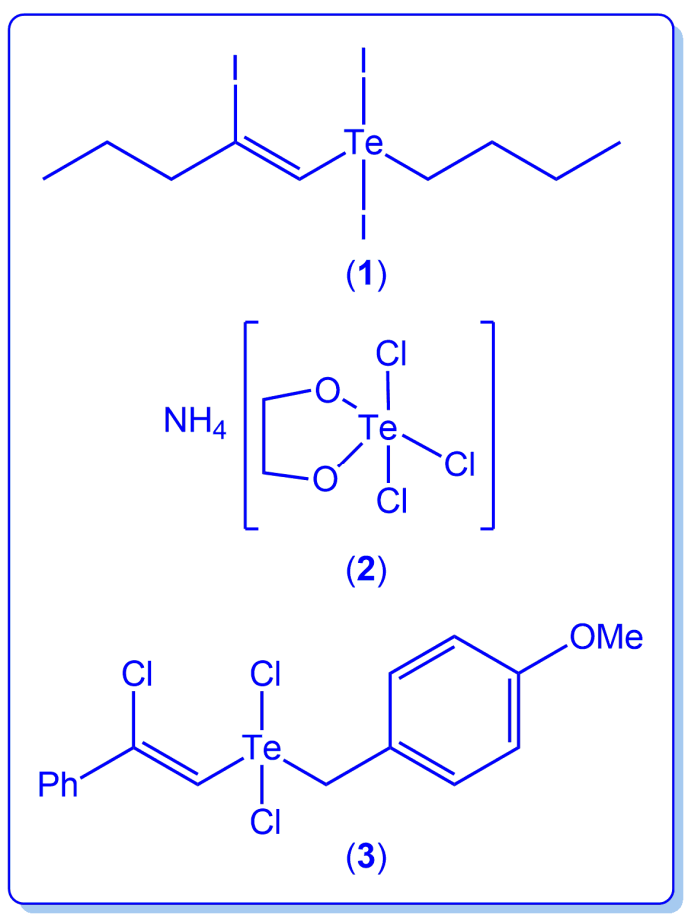

Fig. 1. Chemical diagrams of diiodo(2-iodopent-1-en-1-yl)butyl$\lambda^{4}$-tellane, (1), ammonium trichloro (dioxoethylene- $\mathrm{O}, \mathrm{O}^{\prime}$ )tellurate (2), and dichloro-(2-chloro-phenylvinyl)-4-methoxyphenyltellurium(IV) (3).

The important role of Cat B is indicated in a variety of human disease. Amongst these is tumour metastasis [5], as the metastatic potential of cancer cells is moderated by Cat B [6]. Along with other proteases, Cat B is considered both as a biomarker and a therapeutic target, especially in malig-

Author Title

Ignez Caracelli, *I Julio Crystallographic, DFT and docking (Cathepsin B) studies on an

File Name 
nant melanoma [7]. Neurodegenerative disorders are also thought to involve a role for Cat B [8]. In patients afflicted with rheumatoid arthritis, a disorder associated with the degradation of the extracellular matrix components [9], Cat B has been reported to be up-regulated [10]. Thus, Cat B presents an important target in developing therapies in cancer, arthritis and other disease. This being the case, the generation of selective inhibitors of Cat B is a definite option in drug development. Good inhibitors, as discussed below, have been shown to typically bind amino acids in the $\mathrm{S} 1$ ' and $\mathrm{S} 2$ ' sub-sites [2].

In this context, the tellurium atom in a number of organotellurium compounds has been shown to bind sulphur at the Cys29 site thereby rendering the protein inactive [912]. The most promising tellurium-based therapeutic agent, ammonium trichloro (dioxoethylene-O, $\mathrm{O}^{\prime}$ )tellurate (AS101), 2 in Fig. 1, was the first tellurium compound shown to inhibit non-lysosomal Cat B $[11,13]$. In developing new therapeutic organotellurium(IV) compounds, Cunha et al. showed organotelluranes to be irreversible inhibitors of cysteine cathepsins [12]. Further, strategic modification of substituents can be exploited to alter specificity for different cathepsins, e.g. Cat B, L, S and K, and to relate inhibition efficiency to sub-site specificity [12]. In the present study, a docking study of those compounds, i.e. dichloro-(2-chloro-phenylvinyl)-4-methoxyphenyltellurium(IV) (3 in Fig. 1), was performed to understand the inhibition mechanism [14].

As a continuation of on-going interest in tellurium compounds and their activity in biological environments, the present docking study of a mixed alkyl/alkenyl derivative, 1, was undertaken. The study was motivated in order to determine whether inhibition of Cat B by related compounds required the present of an aryl group(s). The present report details the crystal structure determination of $\mathbf{1}$, its geometry optimised structure as well as docking studies in Cat B.

\section{Experimental}

\section{Synthesis and crystal growth}

Compound 1 was synthesised and characterised as per the literature procedure [15]. Crystals for the X-ray structure determination were obtained by slow evaporation of its chloroform/petroleum ether $(1 / 1 \mathrm{v} / \mathrm{v})$ solution.

\section{Crystal structure determination}

Intensity data for $\mathbf{1}$ were measured at $98 \mathrm{~K}$ on a Rigaku AFC12 $/$ SATURN724 diffractometer fitted with MoK $\alpha$ radiation $(\lambda=0.71073 \AA)$. Data processing and absorption corrections were accomplished with CrystalClear [16] and

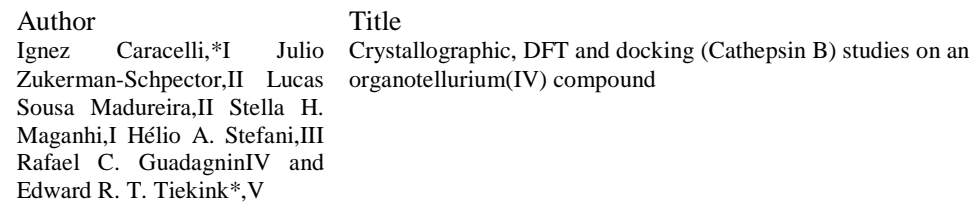

File Name

Te_revised.docx 
ABSCOR [17], respectively. Unit cell data, X-ray data collection parameters, and details of the structure refinement are given in Table 1 . The structure was solved by direct methods [18] and full-matrix least-squares [19] refinement on $F^{2}$ (anisotropic displacement parameters and $\mathrm{C}$-bound $\mathrm{H}$ atoms in their idealised positions). A weighting scheme of the form $w=1 /\left[\sigma^{2}\left(F_{\mathrm{o}}^{2}\right)+(0.055 P)^{2}+2.057 P\right]$ where $P=\left(F_{\mathrm{o}}^{2}+2 F_{\mathrm{c}}^{2}\right) / 3$ was introduced. The maximum and minimum residual electron density peaks of 1.47 and $2.26 \mathrm{e}^{-3}$, respectively, were located 0.91 and $0.77 \AA$ from the Te atom. Two reflections, i.e. ( $\left.\begin{array}{lll}3 & 1 & 2\end{array}\right)$ and $\left(\begin{array}{lll}5 & 9 & 2\end{array}\right)$, were omitted from the final cycles of refinement owing to poor agreement. The programs WinGX [20], PLATON [21], ORTEP-3 for Windows [20], Qmol [22] and DIAMOND [23] were also used in the study.

Table 1. Crystallographic data and refinement details for $\mathbf{1} .^{l}$

\begin{tabular}{|c|c|}
\hline Formula & $\mathrm{C}_{9} \mathrm{H}_{17} \mathrm{I}_{3} \mathrm{Te}$ \\
\hline Formula weight & 633.53 \\
\hline Crystal colour, habit & Colourless prism \\
\hline Crystal size/mm & $0.10 \times 0.20 \times 0.20$ \\
\hline Crystal system & triclinic \\
\hline Space group & $P 1$ \\
\hline$a / \AA$ & $6.599(3)$ \\
\hline$b / \AA$ & $10.917(5)$ \\
\hline$c / \AA$ & $11.451(6)$ \\
\hline$\alpha \prime^{\circ}$ & $86.54(3)$ \\
\hline$\beta /^{\circ}$ & $83.28(3)$ \\
\hline$y^{\circ}$ & $81.13(3)$ \\
\hline$V / \AA^{3}$ & $808.7(7)$ \\
\hline$Z / Z^{\prime}$ & $2 / 1$ \\
\hline$D_{\mathrm{c}} / \mathrm{g} \mathrm{cm}^{-3}$ & 2.602 \\
\hline$F(000)$ & 564 \\
\hline$\mu(\mathrm{Mo} K \alpha) / \mathrm{mm}^{-1}$ & 7.534 \\
\hline Measured data & 8639 \\
\hline$\theta$ range $/^{\circ}$ & $1.8-29.8$ \\
\hline Unique data & 4040 \\
\hline $\begin{array}{l}\text { Observed data } \quad(I \quad \geq \\
2.0 \sigma(I))\end{array}$ & 3888 \\
\hline$R$, obs. data; all data & $0.038 ; 0.040$ \\
\hline$R_{\mathrm{w}}$, obs. data; all data & $0.102 ; 0.104$ \\
\hline$\Delta \rho_{\max , \min } / \mathrm{e} \AA^{-3}$ & $1.47 ; 2.26$ \\
\hline
\end{tabular}

${ }^{1}$ Supplementary Material: Crystallographic data (excluding structure factors) for the structures reported in this paper have been deposited with the Cambridge Crystallographic Data Centre as supplementary publication no. CCDC-1451922. Copies of available material can be obtained free of charge, on application to CCDC, 12 Union Road, Cambridge CB2 1EZ, UK, (fax: +44(0)1223-336033 or e-mail: deposit@ccdc.cam.ac.uk). The list of $\mathrm{Fo} / \mathrm{Fc}$-data is available from the author up to one year after the publication has appeared.

Author Title

Ignez Caracelli, *I Julio Crystallographic, DFT and docking (Cathepsin B) studies on an Zukerman-Schpector,II Lucas organotellurium(IV) compound

Sousa Madureira,II Stella H.

Maganhi,I Hélio A. Stefani,III

Rafael C. GuadagninIV and

Edward R. T. Tiekink*,V
File Name

Te_revised.docx

Date

30.10 .2017
Page 4 (16) 


\section{Computational chemistry}

The calculations were performed using the computational package Firefly [24, 25]. The structures were optimised at the B3LYP/LANL2Zdp level [26-31] with an algorithm based in Quadratic Approximation (QA) [32] and $10^{-5}$ a.u. for the threshold gradient value. The inner electrons for tellurium and iodide were treated with the Effective Core Potential (ECP) approximation [26-31]. The NBO donoracceptor pairs were checked. The interaction energies were calculated according to second-order stabilisation (E2PRT) and steric exchange energies of NBO analyses [33]. Structures, charts and surfaces, were drawn using the wxMacMolPlt and JMol softwares [34, 35].

\section{Docking studies}

The GOLD program (version 4.1.1) [36] was used to perform the docking calculation of "ligand" 1 using a genetic algorithm to explore the full range of ligand conformational flexibility and partial flexibility of the protein binding site. Each conformational result of the ligand has a score (GOLDScore) given by the following sum:

$\mathrm{f}=$ Shb_ext + Svdw_ext + Shb_int + Svdw_int

where Shb_ext is the protein-ligand hydrogen bonding score, and Shb_int the internal hydrogen bonding of the ligand.

The coordinates for the investigated protein, Cat B, were obtained from the PDB and PDBsum sites [37]. Before the calculations, the hydrogen atoms were attached to the protein and all water molecules and the non-proteinatoms removed. On the basis of previous studies [5, 6, 12], which indicate the tellurium atom of related organotellurium(IV) compounds binds the protein at the S-Cys29 site, the docking calculations were conducted with a sphere of $12 \AA$ about the active site with both S-Cys29 and His199 in their ionised forms, i.e. the thiol is pre-activated by transferring its proton to the ring-imine-nitrogen atom leading to the thiolate/ imidazolium tautomer. To inhibit the protein, the tellurium atom must bind to the S-Cys29 [13, 38] indicating that one iodide atom must be a leaving group. Therefore, the following calculations were performed: i) analysis was made with the complete molecule of $\mathbf{1}$ with the protein, and ii) since the tellurium-bound iodide atoms are not equivalent, calculations were performed to ascertain which of these was the better leaving group, i.e. yielding $\mathbf{1}^{\prime}$ which corresponds to 1 less one tellurium-bound iodide, i.e. $\left\{\left[\mathrm{CH}_{3}\left(\mathrm{CH}_{2}\right)_{2} \mathrm{C}(\mathrm{I})=\mathrm{C}(\mathrm{H})\right](\mathrm{nBu}) \mathrm{TeI}\right\}^{+}$. The docking results were plotted using D.S. Visualizer v3.5 [39].

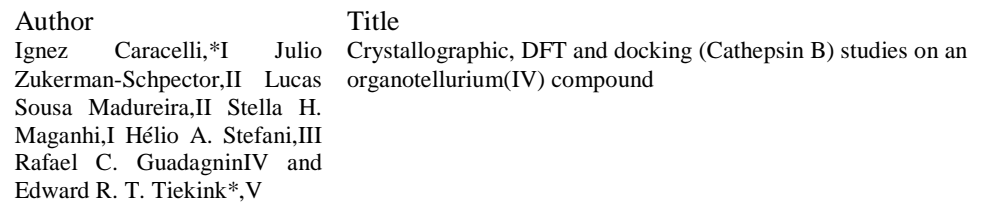

File Name

Te_revised.docx 


\section{Results}

\section{Experimental molecular structure}

The molecular structure of $\mathbf{1}$, as determined by X-ray crystallography, is shown in Fig. 2 and selected geometric parameters are collated in Table 2. The immediate coordination geometry of the tellurium atom is defined by two iodide atoms and two carbon atoms. These donor atoms along with a stereochemically active lone pair of electrons define a distorted trigonal bipyramidal geometry with the iodide atoms being mutually trans defining an axial angle of $176.196(13)^{\circ}$. The tellurium atom also forms a weak intramolecular interaction with the $\mathrm{I} 3$ atom of the vinyl group, $3.5455(19) \AA$, as well as intermolecularly by $\mathrm{I} 2^{\mathrm{i}}, 3.845(2)$ $\AA$; symmetry operation i: -x, 1-y, 1-z. The participation of the $\mathrm{I} 2$ atom in the secondary interaction explains the elongation of the Te-I2 bond length, i.e. 2.9334(13) $\AA$, with respect to the Te-I1 bond length of 2.9083(13) $\AA$. Both of the $\mathrm{Te}^{\cdots} \mathrm{I}$ secondary interactions are less than the sum of the van der Waals radii of Te and I, i.e. $4.04 \AA$ [40]. In consideration of the additional $\mathrm{Te} \mathrm{N}^{\cdots} \mathrm{I}$ interactions that occur approximately normal to the axially-bound iodide atoms, the coordination geometry may be described as distorted $\psi$ pentagonal bipyramidal.

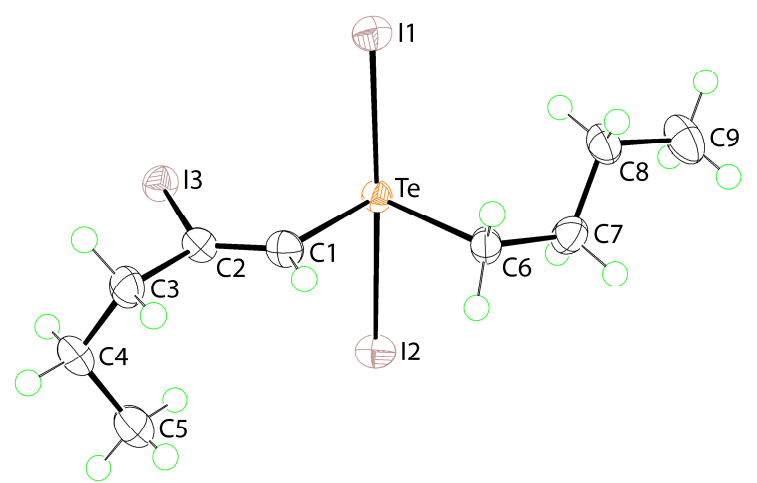

Fig. 2. Molecular structure of $\mathbf{1}$ showing atom labelling and displacement ellipsoids at the $50 \%$ probability level.

Table 2. Summary of key geometric parameters $\left(\AA{ }^{\circ}\right)$ for $1 .^{l}$

\begin{tabular}{|l|l|l|l|}
\hline Parameter & & Parameter & \\
\hline $\mathrm{Te}-\mathrm{C} 1$ & $2.101(5)$ & $\mathrm{Te}-\mathrm{C} 6$ & $2.169(5)$ \\
\hline $\mathrm{Te}-\mathrm{I} 1$ & $2.9083(13)$ & $\mathrm{Te}-\mathrm{I} 2$ & $2.9334(13)$ \\
\hline $\mathrm{Te} \cdots \mathrm{I} 3$ & $3.5455(19)$ & $\mathrm{Te} \cdots \mathrm{I} 2^{\mathrm{i}}$ & $3.845(2)$ \\
\hline $\mathrm{C} 2-\mathrm{I} 3$ & $2.114(5)$ & $\mathrm{C} 1=\mathrm{C} 2$ & $1.328(7)$ \\
\hline $\mathrm{I} 1-\mathrm{Te}-\mathrm{I} 2$ & $176.196(13)$ & $\mathrm{I} 1-\mathrm{Te}-\mathrm{C} 1$ & $88.50(14)$ \\
\hline $\mathrm{I} 1-\mathrm{Te}-\mathrm{C} 6$ & $92.05(14)$ & $\mathrm{I} 2-\mathrm{Te}-\mathrm{C} 1$ & $87.77(14)$ \\
\hline $\mathrm{I} 2-\mathrm{Te}-\mathrm{C} 6$ & $87.37(14)$ & $\mathrm{C} 1-\mathrm{Te}-\mathrm{C} 6$ & $92.74(19)$ \\
\hline $\mathrm{Te}-\mathrm{C} 1-\mathrm{C} 2$ & $124.3(4)$ & $\mathrm{Te}-\mathrm{C} 6-\mathrm{C} 7$ & $112.6(3)$ \\
\hline $\mathrm{C} 1-\mathrm{C} 2-\mathrm{C} 3$ & $124.4(5)$ & $\mathrm{C} 1-\mathrm{C} 2-\mathrm{I} 3$ & $119.2(4)$ \\
\hline $\mathrm{C} 3-\mathrm{C} 2-\mathrm{I} 3$ & $116.4(3)$ & & \\
\hline
\end{tabular}

${ }^{I}$ Symmetry operation i: -x, 1-y, 1-z.

Author Title

Ignez Caracelli, *I Julio Crystallographic, DFT and docking (Cathepsin B) studies on an Zukerman-Schpector,II Lucas organotellurium(IV) compound

Sousa Madureira,II Stella $\mathrm{H}$.

Maganhi,I Hélio A. Stefani,III

Rafael C. GuadagninIV and

Edward R. T. Tiekink*,V
File Name

Te_revised.docx 
The configuration about the vinyl $\mathrm{C} 1=\mathrm{C} 2$ bond is $\mathrm{Z}$. An unexpected feature of the structure is the conformation of the $\mathrm{C}_{5}$ chain. Whereas the n-butyl group exhibits an open, all-trans conformation with the C6-C7-C8-C9 torsion angle being $178.6(5)^{\circ}$, a pronounced kink is observed in the $\mathrm{C}_{5}$ chain as seen in the values of the $\mathrm{C} 1-\mathrm{C} 2-\mathrm{C} 3-\mathrm{C} 4$ and C2-C3-C4-C5 torsion angles of $-118.1(6)$ and $57.5(7)^{\circ}$, respectively.

There are three literature precedents for $\mathbf{1}$, i.e. with the general formula $\left[R C\left(X^{\prime}\right)=C(H)\right](n B u) T e X_{2}$. These, i.e. $X=$ $\mathrm{X}^{\prime}=\mathrm{Cl}$ and $\mathrm{R}=\mathrm{Ph}$ [41], $\mathrm{X}=\mathrm{X}^{\prime}=\mathrm{Br}$ and $\mathrm{R}=\mathrm{CH}_{2} \mathrm{OH}$ [42] and $\mathrm{X}=\mathrm{Cl}, \mathrm{X}^{\prime}=\mathrm{Br}$ and $\mathrm{R}=\mathrm{Cy}$ [43], each feature a $\mathrm{Z}$ configuration about the vinyl bond and an intramolecular $\mathrm{Te}^{\cdots} \mathrm{X}$ interaction.

In the molecular packing, centrosymmetric aggregates are formed via the intermolecular Te...I $2^{\mathrm{i}}$ interactions mentioned above, Fig. 3a. These are connected via vinyl-C1$\mathrm{H}^{\cdots}{ }^{\prime} 1^{1 \mathrm{ii}}\left[\mathrm{C} 1-\mathrm{H} 1 \cdots \mathrm{I} 1^{\mathrm{ii}}=3.04 \AA, \mathrm{C} 1 \cdots \mathrm{I} 1^{\mathrm{ii}}=3.962(5) \AA\right.$, with angle at $\mathrm{H} 1=163^{\circ}$ for ii: $\left.-\mathrm{x}, 1-\mathrm{y}-\mathrm{z}\right]$ interactions into a supramolecular chain along the $c$-axis. Type II halogen bonding interactions [44] between I2 and I3 $3^{\mathrm{iii}}$ atoms [3.829(2) $\AA$ $c f$. sum of their van der Waals radii of $3.96 \AA$ [40]; symmetry operation iii: $-1+\mathrm{x}, \mathrm{y}, \mathrm{z}$ ] link the chains into a supramolecular layer in the $a c$-plane, Fig. $3 \mathrm{~b}$, and these layers stack along the $b$-axis being separated by hydrophobic interactions, Fig. 3c.

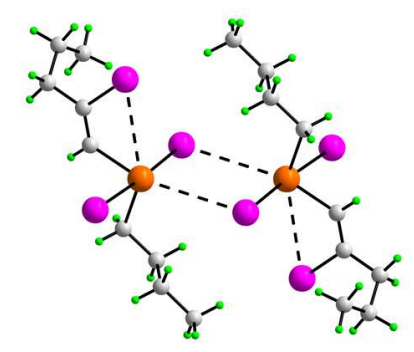

(a)

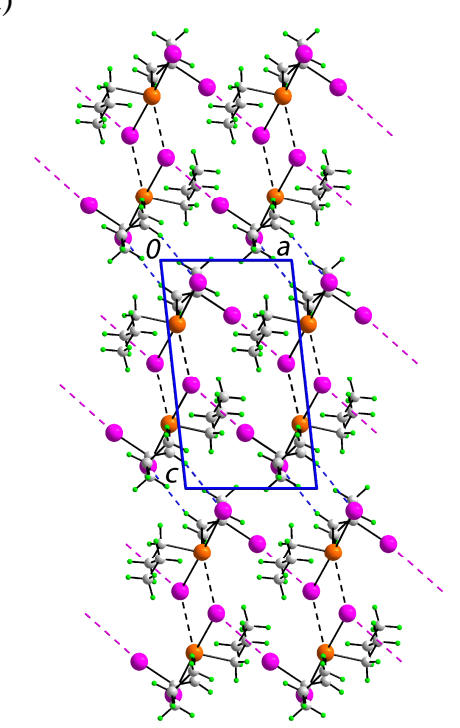

(b)

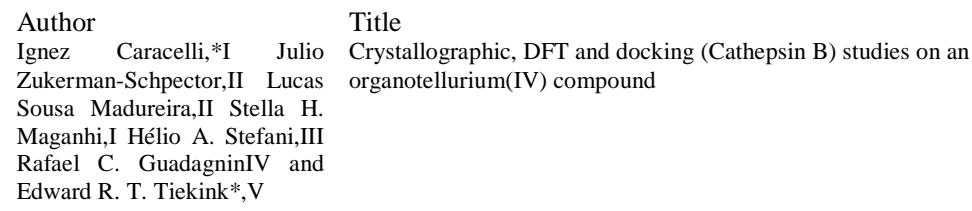




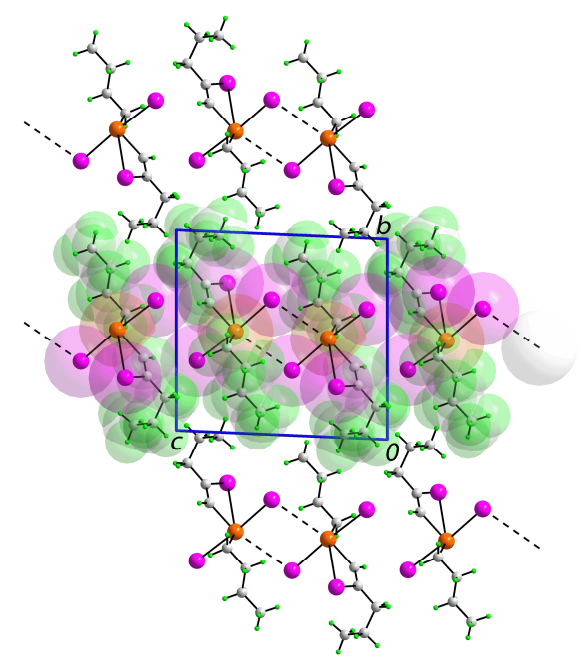

(c)

Fig. 3. Crystal packing in 1: (a) centrosymmetric aggregate mediated by $\mathrm{Te} \cdots \mathrm{I} 1$ interactions. The intramolecular Te $\cdots \mathrm{I} 3$ interactions are also indicated to emphasise the distorted $\psi$-pentagonal bipyramidal geometry, (b) view in projection down the $b$-axis of the unit cell showing the supramolecular layer sustained by $\mathrm{C}-\mathrm{H} \cdots \mathrm{I}$ and $\mathrm{I} \cdots \mathrm{I}$ interactions, and (c) view of the unit cell contents down the $a$-axis highlighting the stacking of layers along the $b$-axis. One supramolecular layer is highlighted in space-filling mode. The $\mathrm{Te} \cdots \mathrm{I}, \mathrm{C}-\mathrm{H} \cdots \mathrm{I}$ and $\mathrm{I} \cdots \mathrm{I}$ interactions are represented as black, blue and pink dashed lines, respectively.

\section{Theoretical molecular structures}

The unrestrained optimization of the structure of $\mathbf{1}$ gave rise to two conformations with very similar minimum-energy (see below). In one conformation the n-propyl substituent at the $\mathrm{C}=\mathrm{C}$ double bond is bent, hereafter named as the closed conformer. In the second, open conformer, the aliphatic substituent is straight, see Fig. 4.

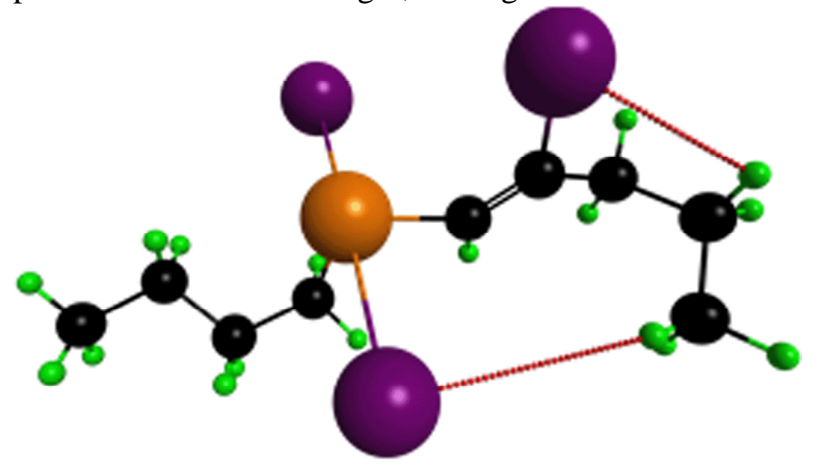

(a) 


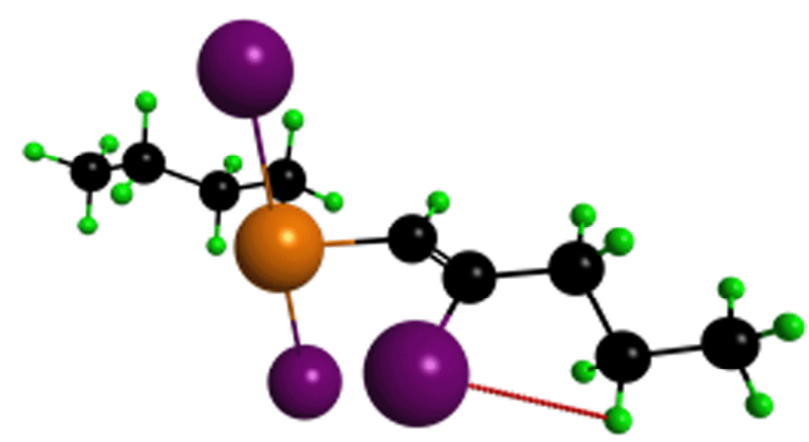

(b)

Fig. 4. Optimised structures of the organotellurium studied herein: (a) closed conformer and (b) open conformer. The $\mathrm{C}-\mathrm{H} \cdots \mathrm{I}$ interactions are shown as red dashed lines.

Both conformations have essentially the same energy, i.e. they are equally stable, Table 3, with the open conformer being marginally more stable. Initially, it was anticipated that the closed conformation would be less stable due to the higher steric hindrance imposed by bent n-propyl substituent (Table 4). According to the data in Table 5, the difference between steric effects is actually small and might be compensated by weak intramolecular $\mathrm{C}-\mathrm{H} \cdots \mathrm{I}$ hydrogen bonds, Fig. 5 and Table 5. The NBO analysis indicates hyperconjugation between the $\mathrm{I} 3$ and methylene- $\mathrm{H}$ atoms. Even though the distance between donor-acceptor atoms of the methyl-H $\cdots \mathrm{I}$ interaction $(\mathrm{C} \cdots \mathrm{I}=4.92 \AA$ and $\mathrm{H} \cdots \mathrm{I}=3.85$ $\AA)$ are $15 \%$ greater than the sum of their van der Waals radii $[40,45]$, the $\mathrm{C} 5-\mathrm{H} 5 \cdots \mathrm{I} 2$ interactions are identified by the NBO analysis as weak hyperconjugation between the lone pair of the iodide and anti-bonding orbitals of the $\mathrm{C}$ (methyl)-H bond $\left(\mathrm{n}_{\mathrm{I}} \rightarrow \sigma^{*} \mathrm{C}-\mathrm{H}\right)$, Fig. 5c, having a secondorder stabilisation energy of $c a$. $0.1 \mathrm{kcal}^{\mathrm{mol}} \mathrm{mol}^{-1}$. It should be noted that the crystallographic structure has a conformation close to that of the closed conformer with a r.m.s. deviation for their superposition of $0.06 \AA$, Fig. 6 .

Table 3. Relative energies ( $\mathrm{kcal} . \mathrm{mol}^{-1}$ ) of the energy-minimised conformers of $\mathbf{1}$.

\begin{tabular}{lccc}
\hline Conformation & $\Delta \mathrm{G}^{\mathrm{e}}(298.15 \mathrm{~K})$ & $\Delta \mathrm{E}$ ZPE & $\Delta \mathrm{E}$ \\
open & 0.0 & 0.0 & 0.0 \\
closed & 0.7 & 0.5 & 0.3 \\
\hline
\end{tabular}

Table 4. Relative steric interactions of the n-propyl substituents (kcal.mol ${ }^{-1}$ )

\begin{tabular}{lc}
\hline Conformation & Steric exchange energy \\
open & 0.0 \\
closed & 0.2 \\
\hline
\end{tabular}

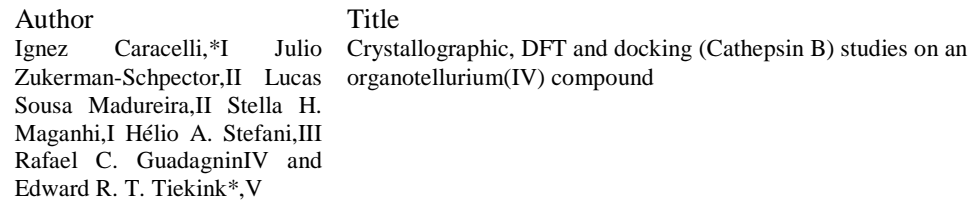


Table 5. NBO analysis of the $\mathrm{C}-\mathrm{H} \cdots \mathrm{I}$ interactions.

\begin{tabular}{lcc}
\hline Conformation & Interaction & E2PRT/kcal.mol ${ }^{-1}$ \\
open & $\mathrm{n}_{\mathrm{I} 2} \rightarrow \sigma^{*}{ }_{\mathrm{C} 5-\mathrm{H} 5 \mathrm{a}}$ & - \\
& $\mathrm{n}_{\mathrm{I} 3} \rightarrow \sigma^{*}{ }_{\mathrm{C} 4-\mathrm{H} 4 \mathrm{a}}$ & -0.3 \\
\multirow{2}{*}{ closed } & $\mathrm{n}_{\mathrm{I} 2} \rightarrow \sigma^{*}{ }_{\mathrm{C} 5-\mathrm{H} 5 \mathrm{a}}$ & -0.1 \\
& $\mathrm{n}_{\mathrm{I} 3} \rightarrow \sigma^{*}{ }_{\mathrm{C} 4-\mathrm{H} 4 \mathrm{a}}$ & -0.3 \\
\hline
\end{tabular}

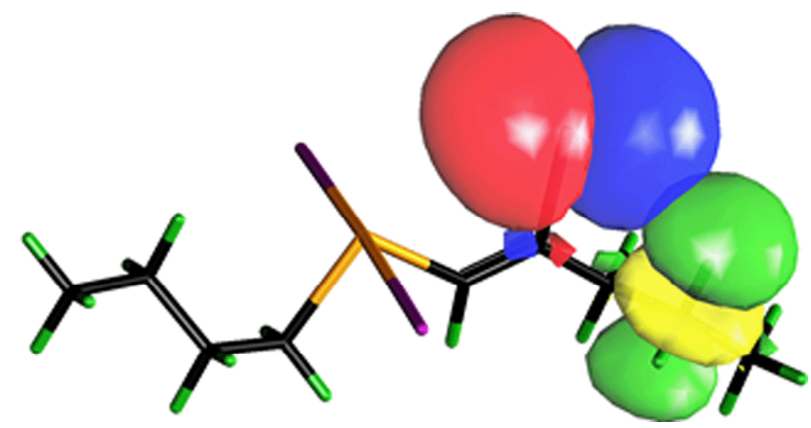

(a)

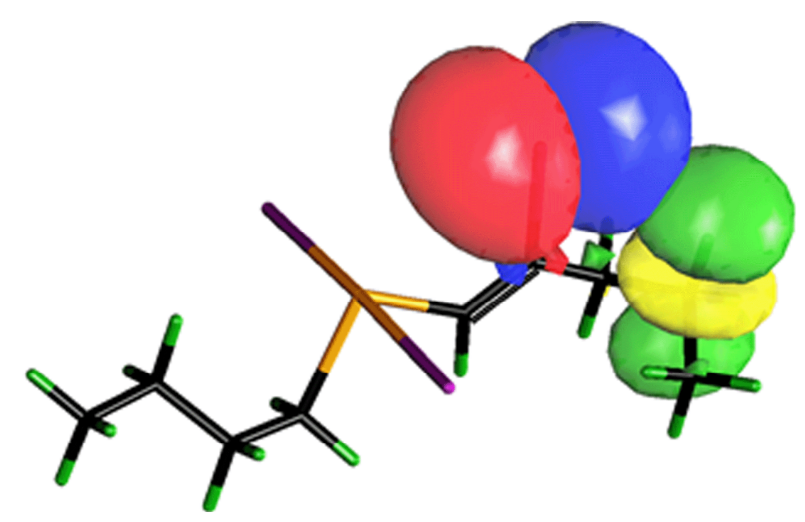

(b)

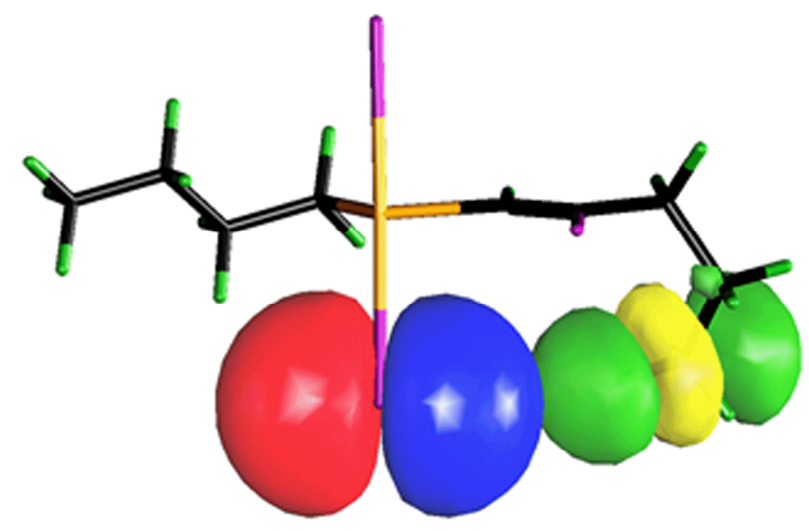

(c)

Fig. 5. Hyperconjugative $n_{I} \rightarrow \sigma^{*} C-H$ interactions: (a) $n_{I 3} \rightarrow \sigma^{*} C 4-$ $\mathrm{H}_{4}$ in open conformer; (b) $\mathrm{n}_{13} \rightarrow \sigma^{*} \mathrm{C} 4-\mathrm{H} 4$ in closed conformer; (c) $\mathrm{n}_{\mathrm{I} 2} \rightarrow \sigma^{*} \mathrm{C} 5$-H5 in closed conformer. Isovalue $=0.02 \mathrm{au} ; \mathrm{n}_{\mathrm{I}}=$ blue and red lobes; $\sigma^{*} \mathrm{C}-\mathrm{H}=$ green and yellow lobes.

Author Title

Ignez Caracelli, *I Julio Crystallographic, DFT and docking (Cathepsin B) studies on an Zukerman-Schpector,II Lucas organotellurium(IV) compound

Sousa Madureira,II Stella H.

Maganhi,I Hélio A. Stefani,III

Rafael C. GuadagninIV and

Edward R. T. Tiekink*,V
File Name 


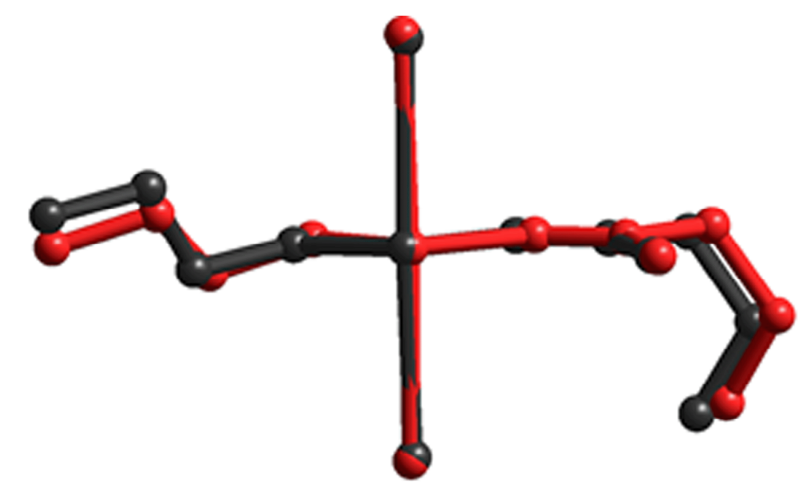

Fig. 6. Overlay of the experimental (black) and geometry optimised closed structure (red) of $\mathbf{1}$. Molecules have been superimposed so that the central $\mathrm{TeI}_{2}$ moieties are coincident, and hydrogen atoms have been removed.

Docking resultsDocking experiments were conducted with $\mathbf{1}$ and $\mathbf{1}$ ', i.e. compound $\mathbf{1}$ less one iodide (see Section Docking studies). The calculations showed that the better leaving atom was I1, giving rise to a GOLDScore of 43.3 cf. 41.3 for I2. Once the I1 atom was removed, a Te-SG bond could be formed, i.e. with the sulphur atom of the Cys 29 residue, at an optimised distance of $2.91 \AA$. This compares well with the results of a search of the Cambridge Structural Data Base [46] gave a range for the Te-S bond lengths of 2.38-3.70 $\AA$ (average $2.73 \AA$ for 1873 observations). Moreover, the same value was found in the crystal structure of the sarcosine oxidase complex with a tellurium compound [47] and in related docking studies [14, 38].

Given that two distinct conformations were found for $\mathbf{1}$, with only a small energy difference indicated from the computational study (see above), both were evaluated in the docking study. It is interesting to note that, regardless of the initial conformation, the final conformation in the active site was the closed form, hereafter Closed 1'. An image showing the interaction of $\mathbf{1}^{\prime}$ with the active site of Cat $\mathrm{B}$ is shown in Fig. 7. In addition to the formation of the Te-S bond, $\mathrm{Te} \cdots \mathrm{O}(\mathrm{Gly} 27)$ and $\mathrm{Te} \cdots \mathrm{H}(\mathrm{Gly} 73)$ interactions are noted; Table 6 collates a summary of all the nearest contacts in the active site. In previous work, similar interactions between the tellurium "ligand" and the active site of Cat B were seen (see below) $[14,38]$. 


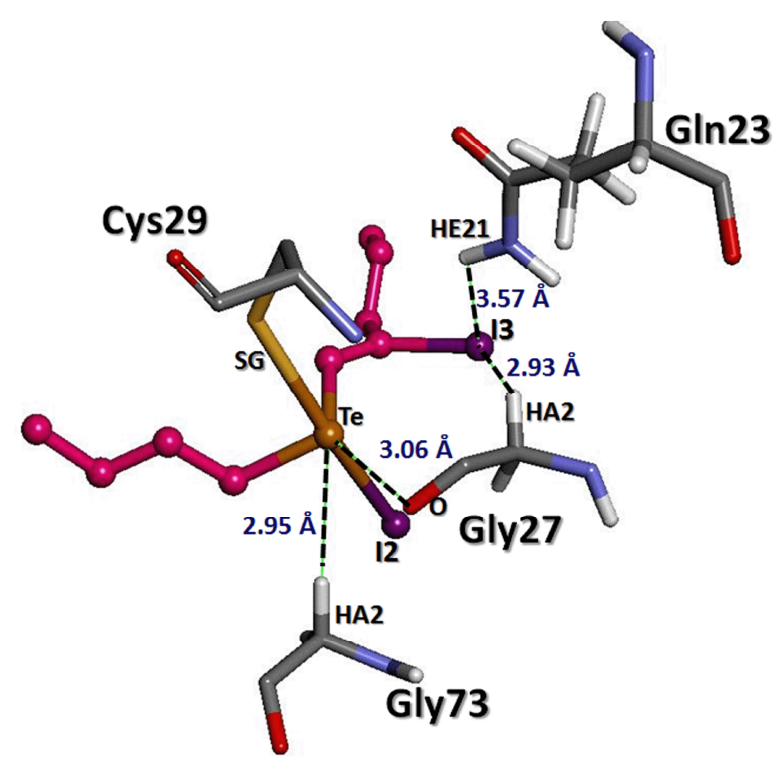

Fig. 7. The coordination around the $\mathrm{Te}$ atom and the $\mathrm{C}$ $\mathrm{H} \cdots \mathrm{I}\left(\right.$ vinyl) interactions for $\mathbf{1}^{\prime}$ bound to the active site of Cat B.

Table 6. Main interactions between Cathepsin B residues and selected pose of the closed 1' ligand.

\begin{tabular}{|c|c|c|c|c|}
\hline \multicolumn{5}{|c|}{ Closed 1'-GOLDScore: $43.3 \mathrm{kcal} / \mathrm{mol}$} \\
\hline Sub-site & $\begin{array}{c}\text { Closed 1'-Cat B } \\
\text { interaction }\end{array}$ & $\begin{array}{l}\text { distance } \\
(\AA)\end{array}$ & $\begin{array}{l}\text { Closed 1' } \\
\text { atom }\end{array}$ & $\begin{array}{l}1 \mathrm{gmy} \\
\text { atom }^{l}\end{array}$ \\
\hline $\mathrm{S} 2{ }^{\prime}$ & I2 - GLU122:OE2 & 2.91 & $\mathrm{I}$ & $\mathrm{O}$ \\
\hline \multirow{2}{*}{ S1' } & H16 GLY197:O & 2.67 & $\mathrm{H}$ & $\mathrm{O}$ \\
\hline & H17 - MET196:O & 2.72 & $\mathrm{H}$ & $\mathrm{O}$ \\
\hline \multirow{9}{*}{ S1 } & Te - GLY73:HA2 & 2.95 & $\mathrm{Te}$ & $\mathrm{H}$ \\
\hline & Te - GLY27:O & 3.06 & $\mathrm{Te}$ & $\mathrm{O}$ \\
\hline & I2 - GLY27:HA1 & 3.20 & I & $\mathrm{H}$ \\
\hline & I3 - GLY27:HA2 & 2.93 & $\mathrm{I}$ & $\mathrm{H}$ \\
\hline & I2 - GLY73: HA2 & 3.27 & I & $\mathrm{H}$ \\
\hline & Te - CYS29:SG & 2.91 & $\mathrm{Te}$ & SG \\
\hline & I2 - ASN72:O & 2.99 & I & $\mathrm{O}$ \\
\hline & H3 - GLY74:O & 2.28 & $\mathrm{H}$ & $\mathrm{O}$ \\
\hline & H4 - GLY74:N & 2.84 & $\mathrm{H}$ & $\mathrm{N}$ \\
\hline \multirow{3}{*}{ S2 } & H1 - GLY198:O & 2.21 & $\mathrm{H}$ & $\mathrm{O}$ \\
\hline & H9 - GLY198:O & 2.72 & $\mathrm{H}$ & $\mathrm{O}$ \\
\hline & H12 - GLY198:O & 2.68 & $\mathrm{H}$ & $\mathrm{O}$ \\
\hline
\end{tabular}

1 1 gmy is the PDB code of the Cat B structure used for the docking experiments.

Fig. 8 shows a detailed view of the immediate coordination environment about the tellurium atom bound to the active site of Cat B. It is remarkable the disposition of the donor atoms matches very closely those found in the crystal structure of 1, Fig 8 insert. 


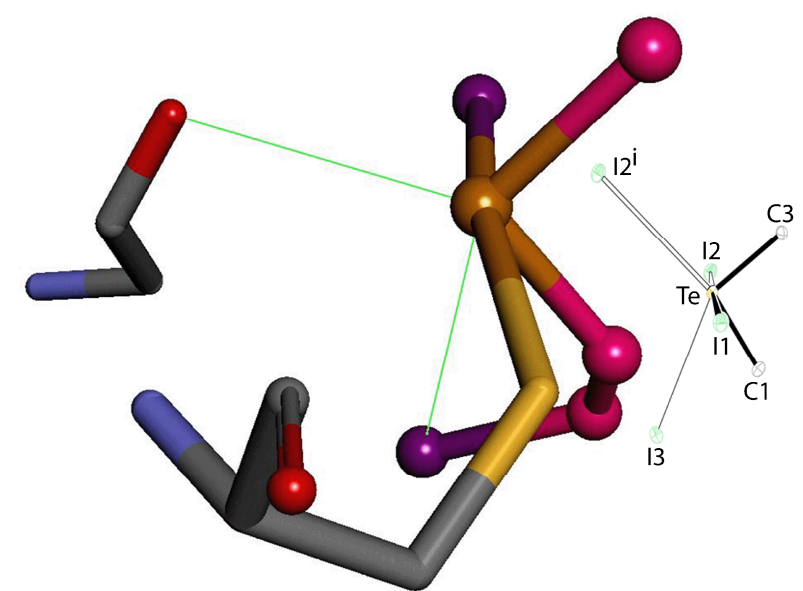

Fig. 8. Detail of the coordination geometry about the tellurium atom in the docked ligand complex, and its comparison with the immediate geometry found in the crystal structure of $\mathbf{1}$.

Finally, Fig. 9 shows the superimposition of the interacting alkyl-derivative $\mathbf{1}^{\prime}$ and benzyl-derivative $\mathbf{3}$ ', i.e. $\mathbf{3}$ less one chloride, in the active site of Cat B. In accord with Schechter and Berger's nomenclature [48], the active site of all proteases comprises several sub-sites. The sub-sites on the N-terminus are named $\mathrm{S} 1, \mathrm{~S} 2, \mathrm{~S} 3{ }^{\cdots} \mathrm{Sn}$, while those on the C-terminus are labelled S1', S2', S3 ${ }^{\prime \cdots}{ }^{-S n}$ '. Previous work revealed that the inhibitory activity is dependent on the binding modes of the ligands and simultaneous binding to the S1' and S2' sub-sites results in significant inhibitory activity. In the present work, the close superimposition of the two ligands, $\mathbf{1}^{\prime}$ and $\mathbf{3}$ ', suggests that as far as interacting with the active site is concerned, the alkyl organotellurium derivative is just as effective in binding as the benzyl derivative.

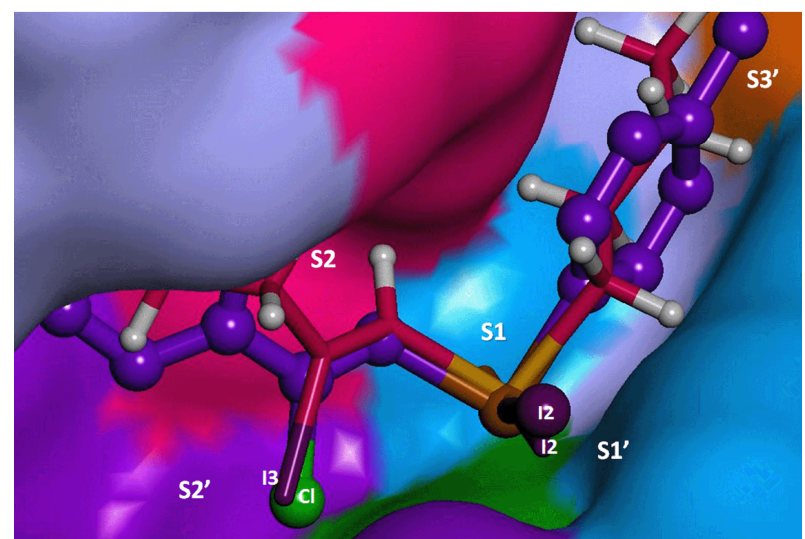

Fig. 9. View of the interaction of ligands 1' and 3' (purple) docked into the active site of $\mathrm{Cat} \mathrm{B}$, highlighting the similarity of the interactions and conformations of the "ligands". The sub-sites are coloured: S1 (blue), S2 (pink), S1' (green), 2' (violet) and 3' (orange). 


\section{Conclusions}

Biologically active organotellurium compounds often inhibit Cathepsin B. Crystallography on an alkyl derivative, $\left[\mathrm{CH}_{3}\left(\mathrm{CH}_{2}\right)_{2} \mathrm{C}(\mathrm{I})=\mathrm{C}(\mathrm{H})\right](\mathrm{nBu}) \mathrm{TeI}_{2}$, 1, reveals a $\mathrm{C}_{2} \mathrm{I}_{2}$ donor set but, allowing for the stereochemically active lone pair of electrons, along with intra- and inter-molecular Te ${ }^{\cdots} \mathrm{I}$ interactions, the coordination geometry is based on a $\Psi$-pentagonal bipyramid. Computational docking of 1', i.e. 1 less one iodide, in Cathepsin B indicates the formation of a Te-S(cys29) bond and a coordination environment analogous to that seen in the crystal structure of $\mathbf{1}$. Notably, the interaction of $\mathbf{1}^{\prime}$ is very similar to those exhibited by benzyl organotellurium species suggesting biological screening of alkyl organotellurium compounds is likely to provide promising outcomes, especially when these derivatives are generally regarded as having low toxicity $[49,50]$.

\section{Acknowledgements}

The Brazilian agencies National Council for Scientific and Technological Development (CNPq$306121 / 2013-2$ to IC, 305626/2013-2 to JZS and 308.320/2010-7 to HAS) and São Paulo Research Foundation (FAPESP-Grants 2012/00424-2 to HAS and 12/22524-9 to SHM) are acknowledged for financial support.

\section{References}

[1] P. D. Greenspan, K. L. Clark, R. A. Tommasi, S. D. Cowen, L.W. Mcquire, D. L. Farley, J. H. Duzer, R. L. Goldberg, H. Zhou, Z. Du, J. J. Fitt, D. E. Coppa, Z. Fang, W. Macchia, L. Zhu, M. P. Capparelli, R. Goldstein, A. M. Wigg, J. R. Dougthy, R. S. Bohacek, A. K. Knap, J. Med. Chem., 2001, 44, 4524.

[2] D. Watanabe, A. Yamamoto, K. Tomoo, K. Matsumoto, M. Murata, K. Kitamura, T. Ishida, J. Mol. Biol., 2006, 362, 979.

[3] M. Shokhen, N. Khazanov, A. Albeck, Proteins: Struct., Funct., Bioinf., 2011, 79, 975.

[4] T. Vernet, D. C. Tessier, J. Chatellier, C. Plouffe, T. Sing Lee, D. Y. Thomas, C. S. Storer, R. Ménard, J. Biol. Chem. 1995, 270, 16645.

[5] M. Buck, D. G. Karustis, N. A. Day, K.V. Honn, B. F. Sloane, Biochem. J., 1992, 282, 273.

[6] P. C. Almeida, I. L. Nantes, J. R. Chagas, C. C. A. Rizz, A. Faljoni-Alario, E. Carmona, L. Juliano, H. B. Nader, I. L. S. Tersariol, J. Biol. Chem., 2001, 276, 941.

[7] Y. Terasawa, T. Hotani, Y. Katayama, M. Tachibana, H. Mizuguchi, F. Sakurai, Cancer Gene Ther., 2015, 22, 188.

[8] T. Mashamba-Thompson, M. E. S. Soliman, Med. Chem. Res., 2015, 24(2), 701.

[9] M. Fonovic, B. Turk, Biochim. Biophys. Acta, 2014, 1840, 2560.

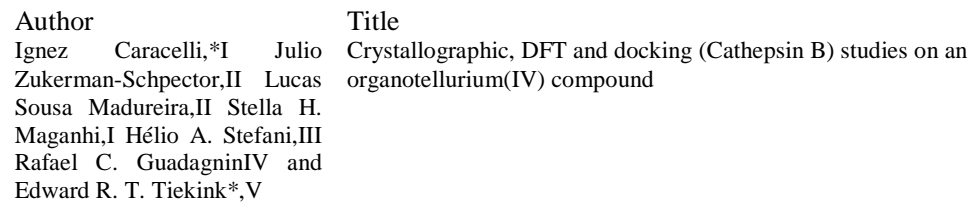

File Name

Te_revised.docx 
[10] V. Turk, V. Stoka, O. Vasiljeva, M. Renko, T. Sun, B. Turk, D. Turk, Biochim. Biophys. Acta, 2012, 1824, 68.

[11] A. Albeck, H. Weitman, B. Sredni, M. Albeck, Inorg. Chem., 1998, 37, 1704.

[12] R. L. O. R. Cunha, I. E. Gouvea, M. F. M. Alves, G. P. Feitosa, D. Brömme, J. V. Comasseto, I. L. S. Tersariol, L. Juliano, Biol. Chem. 2009, 390, 1205.

[13] Y. Kalechman, G. Strassman, M. Albeck, B. Sredni, J. Immunol., 1998, 161, 3936.

[14] I. Caracelli, J. Zukerman-Schpector, S. H. Maganhi, H. A. Stefani, R. Guadagnin, E. R. T. Tiekink, J. Braz. Chem. Soc., 2010, 21, 2155.

[15] J. V. Comasseto, H. A. Stefani, A. Chieffi, J. ZukermanSchpector, Organometallics, 1991, 10, 845.

[16] CrystalClear. User Manual. Rigaku/MSC Inc., Rigaku Corporation, The Woodlands, TX, 2005.

[17] T. Higashi, ABSCOR. Rigaku Corporation, Tokyo, Japan, 1995.

[18] M. C. Burla, R. Caliandro, B. Carrozzini, G. L. Cascarano, C. Cuocci, C. Giacovazzo, M. Mallamo, A. Mazzone, G. Polidori, J. Appl. Cryst., 2015, 48, 306.

[19] G. M. Sheldrick, Acta Crystallogr. C, 2015, 71, 3.

[20] L. J. Farrugia, J. Appl. Crystallogr. 2012, 45, 849.

[21] A. L. Spek, J. Appl. Crystallogr. 2003, 36, 7.

[22] J. Gans, D. Shalloway, J. Mol. Graph. Model. 2001, 19, 557.

[23] DIAMOND, Visual Crystal Structure Information System, Version 3.1, CRYSTAL IMPACT, Postfach 1251, D-53002 Bonn, Germany, 2006.

[24] A. A. Granovsky, Firefly, version 8; http://classic.chem.msu.su/gran/firefly/index.html

[25] M. W. Schmidt, K. K. Baldridge, J. A. Boatz, S. T. Elbert, M. S. Gordon, J. H. Jensen, S. Koseki, N. Matsunaga, K. A. Nguyen, S. Su, T. L. Windus, M. Dupuis, J. A. Montgomery, J. Comput. Chem., 1993, 14, 1347.

[26] A. D. Becke, J. Chem. Phys. 1993, 98, 5648.

[27] T. H. Dunning Jr, P. J. Hay, in Methods of Electronic Structure Theory, Vol. 2, H. F. Schaefer III, ed. PLENUM PRESS, 1977.

[28] P. J. Hay, W. R. Wadt, J. Chem. Phys. 1985, 82, 270.

[29] P. J. Hay, W. R. Wadt, J. Chem. Phys. 1985, 82, 284.

[30] P. J. Hay, W. R. Wadt, J. Chem. Phys. 1985, 82, 299.

[31] C. E. Check, T. O. Faust, J. M. Bailey, B. J. Wright, T. M. Gilbert, L. S. Sunderlin, J. Phys. Chem. A. 2001, 105, 8111.

[32] F. Jensen, J. Chem. Phys. 1995, 102, 6706.

[33] G. E. D. Glendening, J. K. Badenhoop, A. E. Reed, J. E. Carpenter, J. A. Bohmann, C. M. Morales, F. Weinhold, NBO 5. Theoretical Chemistry Institute, University of Wisconsin, Madison, WI, 2004; http://www.chem.wisc.edu/ nbo5

[34] B. M. Bode, M. S. Gordon, J. Mol. Graph. Model.1998, 16, 133.

[35] JMol: An open-source Java viewer for chemical structures in 3D. http://www.jmol.org/

[36] GOLD, version 4.1.1; Cambridge Crystallographic Data Centre: Cambridge, U.K.; http://www.ccdc.cam.ac.uk/products/life_sciences/gold/; G. Jones, P. Willett, R. C. Glen, J. Mol. Biol., 1995, 245, 43.

[37] PDB: http://www.rcsb.org/pdb/home/home.do; PDBSum: http://www.ebi.ac.uk/pdbsum/

\footnotetext{
Author Title

Ignez Caracelli, *I Julio Crystallographic, DFT and docking (Cathepsin B) studies on an Zukerman-Schpector,II Lucas organotellurium(IV) compound

Sousa Madureira,II Stella H.

Maganhi,I Hélio A. Stefani,II

Rafael C. GuadagninIV and

Edward R. T. Tiekink*,V
}

File Name

Te_revised.docx 
[38] I. Caracelli, M. V. Teijido, J. Zukerman-Schpector, M. H. S. Cezari, J. G. S. Lopes, L. Juliano, P. S. Santos, J. V. Comasseto, R. L. O. R. Cunha, E. R. T. Tiekink, J. Mol. Struct. 2012, 1013, 11.

[39] Accelrys DS Visualizer v3.5 (http://accelrys.com/)

[40] A. Bondi, J. Phys. Chem. 1964, 68, 441.

[41] J. Zukerman-Schpector, H. A. Stefani, R. C. Guadagnin, C. A. Suganuma, E. R. T. Tiekink, Z. Kristallogr. 2008, 223, 536.

[42] J. Zukerman-Schpector, H. A. Stefani, D. da O. Silva, A. L. Braga, L. Dornelles, C. da C.Silveira, I. Caracelli, Acta Crystallogr. 1998, C54, 2007.

[43] J. Zukerman-Schpector, I. Caracelli, R. C. Guadagnin, H. A. Stefani, E. R. T. Tiekink, Acta Crystallogr. 2011, E67, o1751.

[44] P. Metrangolo, G. Resnati, IUCrJ, 2014, 1, 5.

[45] S. S. Batsanov, Inorganic Materials, 2001, 37, 871.

[46] F. H. Allen, Acta Crystallogr. B, 2002, 58, 380.

[47] M. A. Wagner, P. Trickey, Z. W. Chen, F. S. Mathews, M. S. Jorns, Biochemistry, 2000, 39, 8813.

[48] I. Schechter, A. Berger, Biochem. Biophys. Res. Commun. 1967, 27, 157.

[49] E. R. T. Tiekink, Dalton Trans 2012, 41, 6390.

[50] H.-L. Seng and E. R. T. Tiekink, Appl. Organomet. Chem. 2012, 26, 655 